\title{
interview interview interview interview interview
}

\section{Call for excellence in research and publishing}

'The South African Journal of Psychiatry has a long history and my intention is to build vigorously on its strengths!'

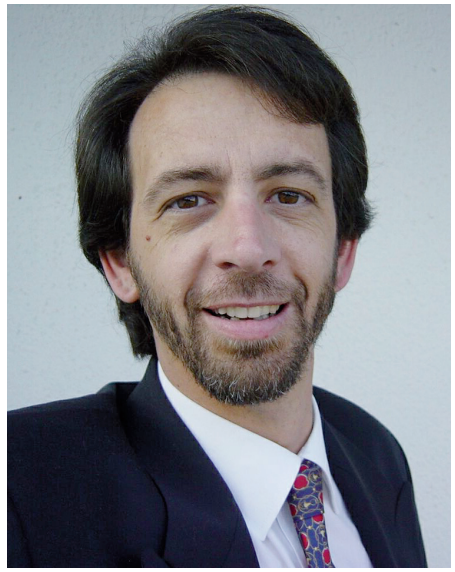

So says Professor Werdie van Staden, psychiatrist and philosopher attached to the Department of Psychiatry at the University of Pretoria and Weskoppies Hospital, and the incoming editor of the SAJP.

Van Staden, who takes over the editorship from Professor Robin Emsley, psychiatrist at Tygerberg Hospital, says that the SAJP has a key role to play in the local psychiatric scene and that it can best achieve this by being locally relevant while at the same time taking its place in the international arena. The journal must be a practical resource that addresses at an academic level the clinical practice, research and educational needs and issues that we face currently in South Africa,' he says.

Van Staden, whose interests range from the philosophy and ethics of psychiatry to the symptomatology and psychopharmacology of schizophrenia and to psychotherapeutic recovery, says a key to the strength of the journal is the quality and relevance of research that is undertaken in the country. And he sees the journal not only as supporting that research, by offering an outlet to make its results more widely known, but also in facilitating both research and education. I would like the journal to encourage local psychiatrists to do good work, whether clinical, research or educational, and ultimately to produce good papers.'

Van Staden notes that conditions are challenging for psychiatrists in South Africa at present and that the demands being made result in them being expected to be 'jacks of all trades'. 'There is a huge need at all levels of the system, particularly at the clinical service delivery level, and there are just too few people to cope with the need,' he says, citing as an example one of the country's teaching hospitals, in which he comments that there is only one appointed psychiatrist, acting in the place of a full psychiatric team.

In addition there are issues around the continuing availability of medications, with patients having to be told that their medication is unavailable or discontinued - and this on top of the ongoing challenges with patients regarding adherence to medications.

All of this impacts on the efficacy of the care that is offered to patients, van Staden says, adding that there are also political issues that need urgent attention in the management of the system. The SAJP is in a good position to deliver scientifically accountable input for deliberations on all of these issues.'

Van Staden, who is also a qualified musician, with a licentiate in music from UNISA and a Fellow of the Trinity College of Music in London, is involved in a number of activities, including holding a visiting senior clinical lectureship at the University of Warwick in the UK. He also serves on the steering committee of the International Network for Philosophy and Psychiatry, and he is the founder and chair of the Philosophy of Psychiatry Special Interest Group of the South African Society of Psychiatrists (SASOP), as well as a member of the Society's national executive.

Van Staden is also serving as convenor of the forthcoming SASOP congress in Swaziland in September, and he enthuses about the programme that is being set up. We are very excited about the several champions of psychiatry both from within South Africa as well as from other countries, who are set to deliver stimulating presentations' he says. 'For example, Professor Perry Bartlett from Australia, who discovered that adults can make new brain cells, something that was thought not possible until recently, will be talking to us on this topic that made the front page of The Times.

Under the theme "Facts and values in psychiatric practice" the conference will address the complexities of scientific evidence as well as those of the ethical and the personal values with which psychiatrists and other mental health practitioners are dealing at the coalface of psychiatric practice,' he says.

Van Staden is no stranger to the written word and in addition to serving on the editorial board of Philosophy, Psychiatry \& Psychology and as a managing editor of Philosophy, Ethics and Humanities in Medicine, he has published widely in books and journals of psychiatry, philosophy, medical ethics and psychology. My message to past and new contributors to this journal is that we are keen to receive and publish high-quality work. We urge every psychiatrist to make submissions to the journal with the view to active participation by its actual owners, as it is after all the official scientific voice of our society. As a forum to put our heads together and promote scientifically sound and clinically relevant discussions, it can only improve the quality of the subject and ultimately delivery at the clinical coalface.

\section{Jonathan Spencer Jones}

